\title{
VAHAN AND ICT-ENABLER OF IMPOSING E-PENALTY FOR TRAFFIC RULE VIOLATOR: AN E-GOVERNANCE ENFORCEMENT
}

\author{
Shiv Kumar Goel ${ }^{1} \&$ Dr. Kavita ${ }^{2}$
}

Abstract-ICT and E-Governance can provide an efficient solution to curb the Traffic rules violations and penalize such violators on the spot with the help of Intelligent Automated System in INDIA. VAHAN is one of the enabler to impose infringement penalty on citizens under the influence of e-Governance enforcement on citizens.VAHAN keeps the record of every vehicle and its owner at district and village level under the purview of RTO and ARTO. This data will be helpful to impose the penalty on vehicle owner globally. VAHAN data is centrally available at Nation Level and whenever and wherever a vehicle violate the traffic rule can easily identified with the help of this Nation level centralised repository and owner will be imposed with an automatic penalty through Intelligent Automated System.

Keywords-VAHAN, ICT, e-Governance, EPS, VSC

\section{INTRODUCTION}

According to W.H.O. (World Health Organization) after the health issue in the society; the next challenge is to control the Road accidents, due to which many innocent people have lost their lives. Many Prominent People like Late Shree Gopi Nath Munde, children and many innocent people have lost their lives on road accident due to errant driving and jumping of the signals on the road. Government has installed CCTV cameras in city to capture such offenders and taking lot of initiative to penalize them. Government has also increased the penalty amount for such offences but the enforcement is not at the place to penalize them forcibly. With the help of ICT and VAHAN, enforcement of the penalty is possible under e-Governance influence. The National e-Governance Plan (NeGP), a government initiative, providing a massive countrywide infrastructure reaching down to the remotest of villages and hence large-scale digitization of records is taking place to enable easy, reliable data access over the internet[1-2]. The main objective of NeGP is to transform government citizen services from their present manual delivery to digital delivery. VAHAN data is available at district level, state level and village level also [3-4]. This whole process involves different types of communication (i.e. horizontal, vertical,upward and backward) across the different departments which can be a very complex but ICT has made it very efficient and comparatively easier than before. ICT is an enabler to deliver services to the citizens conveniently in urban and rural areas in a cost-effective manner. ICT has made easier and faster the flow of information between Government and citizens and it has also changed the medium of interaction between them [2]. E-governance supported by ICT helps in combining people, processes, technology and information in order to increase the efficiency of the Government operations and has reached to millions of the people across the country.

VAHAN: An application is developed by NIC Headquarter Delhi for registration of vehicles and road tax clearance by the RLA (Registration and Licensing Authority) / RTA (registration and Transportation Authority). It helps the department to Register Vehicle, Collect tax, Issue various certificates and permits and Record the fitness of vehicles.

\section{Work Flow for Generating RC}

Step 1: Fees Collection through computer.

Step 2: Entering Registration Details.

Step 3: Printing Registration Certificates.

VAHAN keep all the records of Vehicle like registration number, engine number, and model of vehicle, make of vehicle and the owner name, address and other credential of vehicle's owner as well. This data is digitized and available at various levels of RTOs. VAHAN, the vehicle registration software, and SARATHI, driving license services software, has been implemented in 29 States/UTs and now being implemented in other states also.

\footnotetext{
${ }^{1}$ Research Scholar, Departnment of C.S and I.T., JV Women's University Jaipur, Rajasthan, INDIA

${ }^{2}$ Associate professor, Departnment of C.S and I.T., JV Women's University Jaipur, Rajasthan, INDIA
} 


\section{EXISTING SYSTEM}

Now days in many Metropolitan cities, CCTV cameras captured the image of the vehicles on road at different place throughout the city. Traffic department of the city keep watches on such vehicles those who violate traffic rules. They caught such vehicles at control room of CCTV camera and send the e-challan of the infringement to their recorded residential address according to the VAHAN database. Due to the mismatch of the current address and the recorded address, e-challan does not reach to the offender in many cases. Even if the e-challan received by the offender, they do not bother to pay the penalty amount as there is no tracking of such cases. Moreover in this existing system there is no record of whether this is the first infringement for this offender or the offender is a repetitive offender. In existing system offender doesn't have fear to be penalized even though the offender has violated traffic rules which encourage them for repetitive offences. Other existing penalty system in INDIA like on time penalty, e-challan etc. are not able to assure to impose the forcible penalty to the offenders to discourage them for not to do the offence again, due to some limitations and due to some human intervention in present system. Current System creeps the corruption in the traffic department also. However due to CCTV based e-challans there is a leap in Number of challans i.e. offenders are caught in violating traffic rule more compare to other approaches but enforcement of penalty must be imposed to penalize them forcibly.

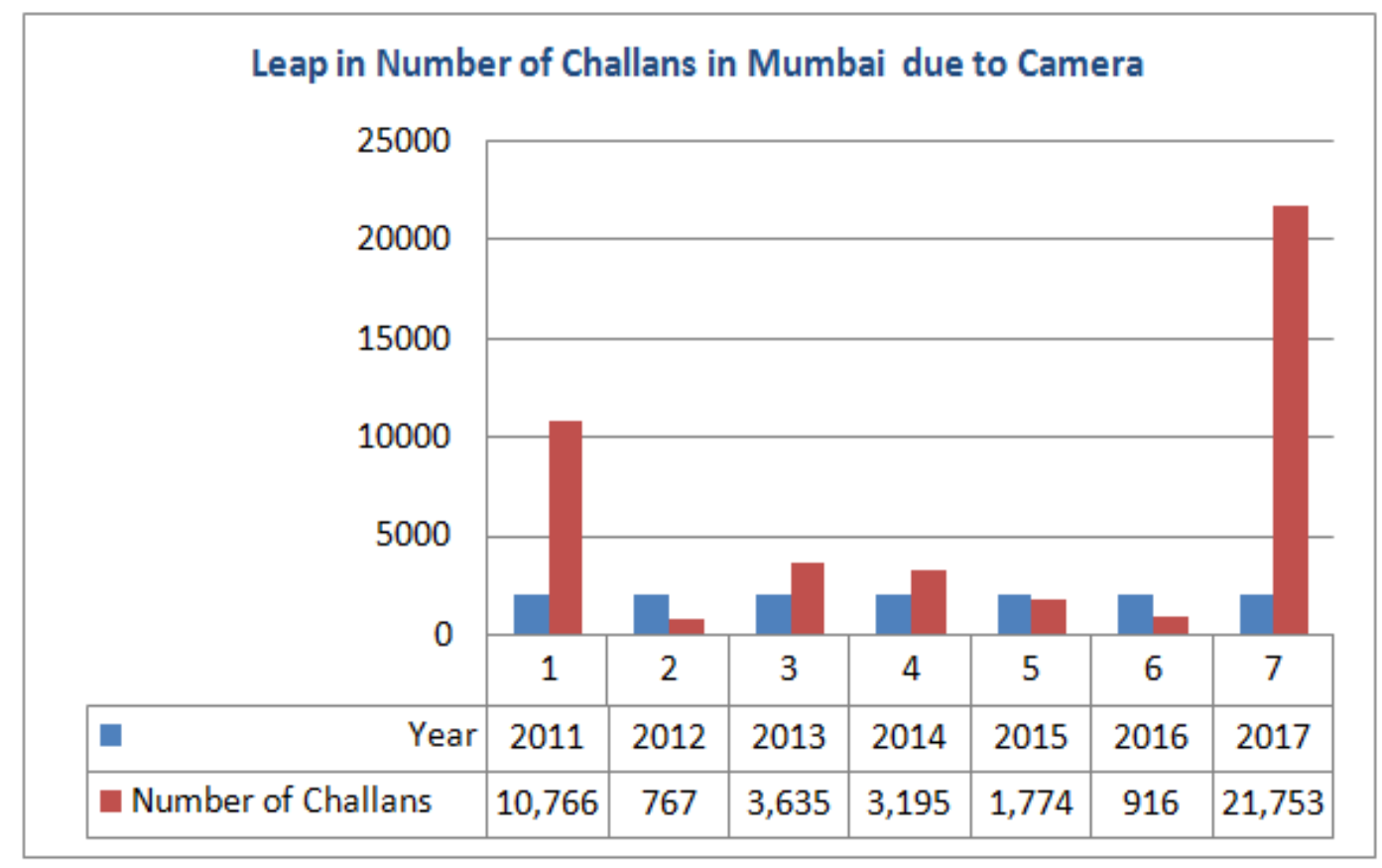

Figure 1. Result showing the rise in challans due to Camera Approach in Mumbai

\section{PROPOSED SYSTEM}

This proposed approach will use the VAHAN data which is available at different level i.e. village level, district level, state level and finally at Nation level centralized repository. VAHAN issues Registration Number to the vehicle and Registration Certificate (R.C.) to the owner having different attributes like Vehicle data and as well as owner's data like address and contact number etc. At the time of registration every vehicle owner has to fill an ECS form and link the AADHAAR Card and Bank details mandatorily with the registration number of vehicle as G2C enforcement. This information of linking the Bank detail with the Registration Number will help the Intelligent Electronic Penalty System to deduct the penalty amount forcibly and SMS will be sent to the registered mobile number with that vehicle. IEPS will also keep the record of offence associated with that particular vehicle and if same vehicle is involved in offence again then two fold amount will be deducted and owner will be informed for the same, so the same vehicle owner will be forcibly penalized and as well as will not make courage to do the offence next time. If the same offender involved in violation of traffic rule more than two times, vehicle registration will be cancelled and offender has to pay a hefty amount which will be deducted directly from their linked account and owner will be informed through SMS and warned to get renew the RC. Such stringent rules will forced the citizen for not to repeat the offence and will reduce the unwanted loose of lives on road. This proposed system will reduce the operating cost of sending the e-challan to the addressee and as well as it will enforce automatic deduction of penalty amount. In this system penalty can be imposed globally i.e. interstate vehicles also as data is centralized available and those vehicles who violates the traffic rules in any city can be penalized through IEPS. 

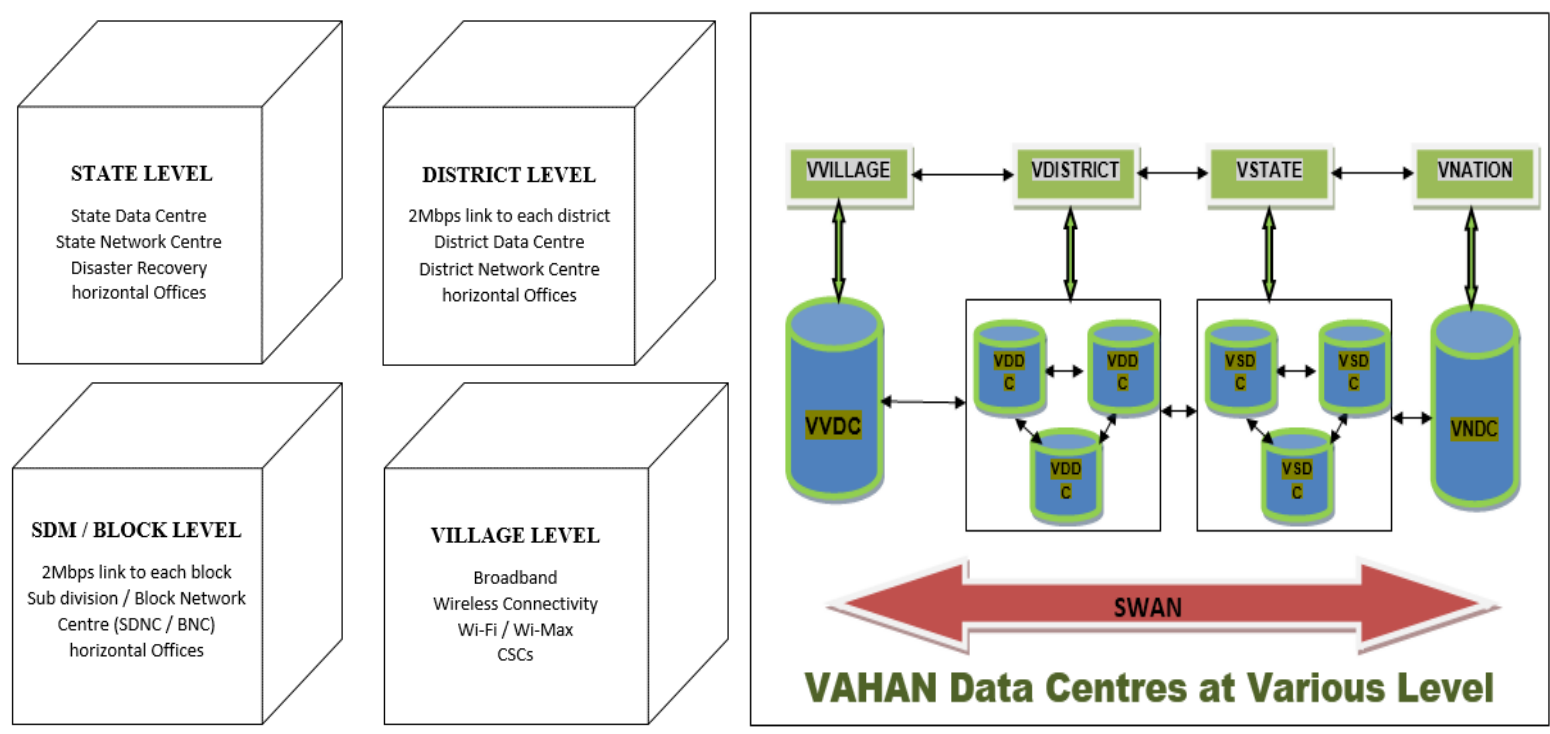

Figure 2. Data centers and VAHAN details at various levels

\section{IMPLEMENTATION STEPS OF PENALTY SYSTEM}

\subsection{Intelligent Electronic Penalty (IEPS) System}

Whenever an offender violates the traffic rule, the penalty amount can be deducted from the vehicle owner's account with the help of Intelligent Electronic Penalty System and the SMS will be sent to the owner at the same moment. This system will work as the working model of ATM Banking system. In this system, penalty can be deducted from the account of a vehicle owner in two ways-

1. At the time of registration of vehicle, owner will be asked to fill the ECS (Electronic Clearance System) /Vahan Smart card (VSC) form and penalty imposed will be deducted from the owner's account.

2. Government has made mandatory that AADHAAR CARD should be linked with the BANK Account to get some benefit so AADHAAR card, can also be linked to the Vehicle Registration number and penalty amount can be deducted from the bank account linked with this AADHAAR CARD.

\subsection{Framework of IEPS}

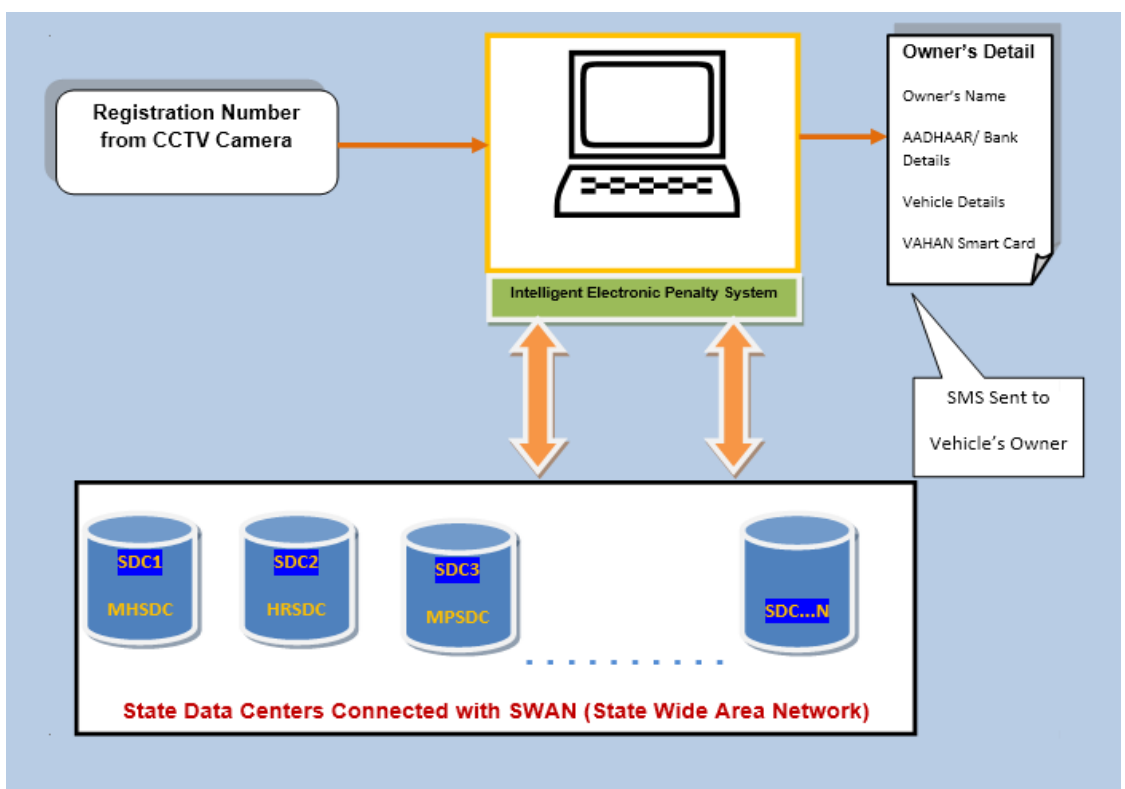

Figure 3. IEPS Frame work to Impose e-Penalty 


\subsection{Implementing Steps of IEPS}

IEPS system will work as follows

Step1. Extracted registration number received (Example: MH 46 N595) will be matched with the state in which the vehicle belongs to for this purpose the first two character will identify the state. Here MH i.e. Maharashtra

Step2. After identifying the state, next step is identifying the RTO area, for this next two digits are responsible. Example MH 46 then 46 belongs to Kalamboli R.T.O. in Navi Mumbai.

Step 3.After this the next numbers are Registration number, here in example N595 will be matched with the registration digitalized data of VAHAN with the help of Registration Certificate (RC)handled by R.T.O and Intelligent Expert System (IES).

Step4. After this the owner's detail will be identified and penalty will be deducted through ECS or from Bank account linked with the owner's AADHAR CARD.

\section{FUTURE SCOPE}

Automatic deduction of penalty can also be implemented by issuing the Smart Card (Plastic Money). This Smart Card will be issued at the time of Vehicle Registration and can be recharged time to time according to the threshold amount balance in the card. Cloud "Meghraj" can also be used for SDC and other Data centres at various levels.

\section{CONCLUSION}

This work proposed a system which will help the government and as well as society in many ways. Government may generate more revenue by Traffic control Department as there is no chance of bribe in e-Penalty system so the bribes have either been eliminated or significantly reduced and hence corruption free Traffic Department. Citizens will not be harassed by the Traffic Control Officer which is a very general case in case of an offender caught by a police officer after violating the traffic rules .If a Vehicle caught more than one time in infringement of Traffic rule it can be penalised two or more fold the previous amount which is not possible in present scenario manually. This system can work like the ETC (Electronic Toll System) model for automatically deduction of penalty amount and for interaction or communicate among the village, district, state and nation wise data; it can work like Bank Transaction System Model. So proposed system can be used for penalized the offenders who violet the traffic rules globally.

\section{REFERENCES}

[1] Kalsi N.S., Kiran R. and Vaidhya S.C. (2013) "ICT and Good Governance: A Study of Indian Environment" white paper published: E-Governance in Practice, 10-25.

[2] Swaminathan A. and Sekar P. (2012), "Information and Communication Technology (ICT) and Society", International Journal of Computer Applications (IJCA) and proceeding International Conference on E-Governance \& Cloud Computing Services (EGov'12), 16-19.

[3] https://vahan.nic.in/nrservices/ (National Register e-Services of Registered Vehicles)

[4] www.tn.nic.in/tnhome/projectfiles/brochure-transport.pdf(Vahan and Sarathi, E-Governance at Regional Transport Offices in Tamil Nadu)

[5] Akiwate B., Suryavanshi M. and Gurav M. (2015) "Automated Toll Collection", International Journal of Advanced Research in Computer $\quad$ Science and Software Engineering(IJARCSSE),ISSN: 2277 128X, 5(10) :276-280.

[6] Bharti A.K., and Dwivedi S.K. (2011), "E-Governance in Public Transportation: U.P.S.R.T.C.-A Case Study", International Conference on Software and Computer Applications (IPCSIT), 9, IACSIT Press Singapore.

[7] Dambe A., Gandhe U., Bendre V. (2013), "Automatic penalty charging for violation of traffic rules", International Journal of Advanced Research in Electrical, Electronics and Instrumentation Engineering (IJAREEIE), ISSN:2320 3765, 2(2):769-771.

[8] Dutta A. and Syamala D. M. (2015), "E-Governance Status in India", International Journal of Computer Sciences and Engineering (IJCSE), ISSN: 2347-2693,3(7),1-6.

[9] Gandhi V. and Kumbharana C. K. (2017), "E governance for Regional Transport Offices in India" , International Journal of Scientific and Research Publications (IJSRP), ISSN 2250-3153, 7(7) : 413-420.

[10] Jain N., Agnihotri B. P. and Verma A. (2013), "Impact Assessment of E- Governance in India", International Journal of Engineering and Management Research (IJEMR), ISSN 2250-0758, 3(6): 128-131.

[11] Saxena S. and Agarwal D. (2015), "A Review of Barriers Found in E-Governance Projects in Indian States", International Journal of Advanced Research in Computer Science and Software Engineering Research (IJARCSSE), ISSN: 2277 128X,5(11),305-311.

[12] Shah M.(2007), "E-Governance in India: Dream or reality?", International Journal of Education and Development using Information and Communication Technology (IJEDICT),3(2):125-137.

[13] Singh S., Pal S. and Badhan R.K. (2015), "Detection of Traffic Violation at Unmanned Road Crossing in Urban Areas", International Journal of Computer \& Mathematical Sciences (IJCMS), ISSN:2347 - 8527,4(Special Issue). 